Bangladesh Journal of Anatomy January 2011, Vol. 9 No. 1 pp 49-52

\title{
Effect of Fenugreek (Methi) on Amount of Connective Tissue in Thymic Sections in Streptozotocin-induced Diabetic Rats
}

\author{
DK Mondal ${ }^{1}$, MMM Ahmed $^{2}$, PK Chowdhury ${ }^{3}$, A Khanom ${ }^{4}$, S Mohal $^{5}$, S Ara ${ }^{6}, \mathrm{KM} \mathrm{Shamim}^{7}$
}

\begin{abstract}
:
Context: Diabetes mellitus causes a marked increased in amount of connective tissue in thymus. Fenugreek has the hypoglycaemic effect. The study was carried out to find out whether Trigonella foenumgraecum (fenugreek seeds/methi seeds) has got any preventive role against the increment in amount of connective tissue in thymic section in diabetes mellitus.
\end{abstract}

Study type: an experimental study on Long Evans rats which were divided into three equal groups depending on their different sorts of dietary feeding and drug treatment.

Setting: Anatomy department of the then IPGMR (Institute of Post Graduate Medicine and Research) at present BSMMU (Bangabandhu Sheikh Mujib Medical University) and BIRDEM (Bangladesh Institute of Research and Rehabilitation in diabetes, Endocrine \& Metabolic Disorders).

Subjects: Fifty eight healthy young Long Evans rats of either sex weighing 72 to 174gm aged between 50 to 60 days were used in this study.

Main outcome measures: variation in amount of connective tissue in thymic sections in different groups of rats.

Result: in the nondiabetic control group the increased in amount of connective tissue in thymic section is lower than in diabetic control group. On the other hand, the increased in amount of connective tissue in thymic section in the fenugreek-treated diabetic rats is also lower than the amount of connective tissue in thymic section in diabetic control group but it is more or less similar to the amount of connective tissue in thymic section in nondiabetic control group.

Conclusion: Fenugreek showed a tendency of acting against the increased in amount of connective tissue in thymic section in Streptozotocin-induced diabetes mellitus. However, further investigations are recommended for establishing fenugreek as a safe, useful effective agent to minimize the increment in amount of connective tissue in thymic section improving the diabetic condition by acting as antidiabetogenic agent.

Key words: Diabetes mellitus, Connective tissue, Fenugreek, Thymus.

1. Professor, Department of Anatomy, Diabetic Association Medical College, Faridpur.

2. Assistant Professor, (C.C) Department of Physiology, Khulna Medical College, Khulna.

3. Assistant Professor (C.C.), Department of Biochemistry, Khulna Medical College, Khulna.

4. Assistant Professor (C.C.), Department of Gynae Onchology, National Cancer Research Institute \& Hospital, Mohakhali, Dhaka.

5. Assistant Professor, Department of, Anatomy Marks Dental College, Mirpur-14, Dhaka.

6. Professor \& Head, Department of Anatomy, Dhaka Medical College, Dhaka.

7. Professor, \& Chairman, Department of Anatomy, BSMMU, Dhaka.

Correspondence: DK Mondal

\section{Introduction:}

Worldwide prevalence of diabetes mellitus is a serious health problem. Now a day in Bangladesh a high proportion of diabetics are registered to different clinic and institutes. Only Bangladesh Institute of Research and Rehabilitation in diabetes, Endocrine \& Metabolic Disorders (BIRDEM) has registered 1,78,015 cases in 1997, which is more than 15,000 higher than that of previous year. Although it is understandable that many of the diabetic patients especially in the rural area have not registered themselves to any diabetic clinic or hospitals and many other still remain undiagnosed. 
Fenugreek is a leguminous herb, cultivated in the Indian subcontinent, in the Mediterranean region and in the North Africa. ${ }^{1}$ It is also named as 'methi' in this subcontinent which has the hypoglycaemic effect due to its alkaloid 'trigonelline' was reported as early as in 1948 by Fournier, who showed the hypoglycaemic effect in animals ${ }^{2}$, in humans NIDDM $^{1,3,4}$ and in IDDM patients. ${ }^{5}$

Diabetes mellitus causes increment in amount of connective tissue in thymic section of the involuted thymus gland ${ }^{6}$. It may be hypothesized that fenugreek (Methi) being an antidiabetic agent may also be used to minimize the increment of amount of connective tissue in thymic section by inhibiting involution of the thymus in diabetes mellitus.

\section{Materials and Methods:}

A total number of 58 young rats of either sex of Long Evans strain were used in this experiment. They were young rats of 50 to 60 days old, weighing between 72 and $174 \mathrm{gm}$. Among them 10 rats were treated with vehicle (citrate buffer solution at the $\mathrm{pH}$ 4.5) only used as non-diabetic control rats (Group A) and 20 rats were treated with vehicle and Streptozotocin found as diabetes, 10 of which were treated as diabetic control group (Group B) and rest 10 (1 died, 1 escaped) were treated again with defatted fenugreek (methi) powder at a dose of $1.25 \mathrm{gm}$ in $10 \mathrm{ml}$ of demineralized water per $\mathrm{kg}$ body weight per day to control the diabetes mellitus and was called as fenugreek treated diabetic group (Group C).

After sacrifice (on the 13th day from the day of STZI Vehicle injection) of the rats, the thymus gland was dissected carefully and for this study a good section of right thymic lobe of each rat was stained with Gallego's iron fushin stain. Magnified photographs of each were taken as for measurement connective tissue in the thymic lobe. In this procedure of photography the magnification was kept constant by ensuring that the distances of the projector and the camera from the board, the focal length of the camera lens and the magnification factor applied during printing remain constant. Comparison of the photographs with each other gave a rough idea about the relative amount of connective tissue present in the thymuses of the three groups of rats.

\section{Observations and results:}

Figure 1 shows the amount of connective tissue in thymic section in non-diabetic control, diabetic control* Fenugreek-treated diabetic rats. Comparison of the photographs with each other gave a rough idea about the relative amount of connective tissue present in the thymuses of the three groups of rats.

Increased in amount of connective tissue in the histological section of the thymus in the nondiabetic group was lower than that of the value in diabetic control group. On the other hand, the increment in amount of connective tissue in thymic section in the fenugreek-treated diabetic group was also lower than that of the diabetic control group but more or less nearer to the value in the nondiabetic group.

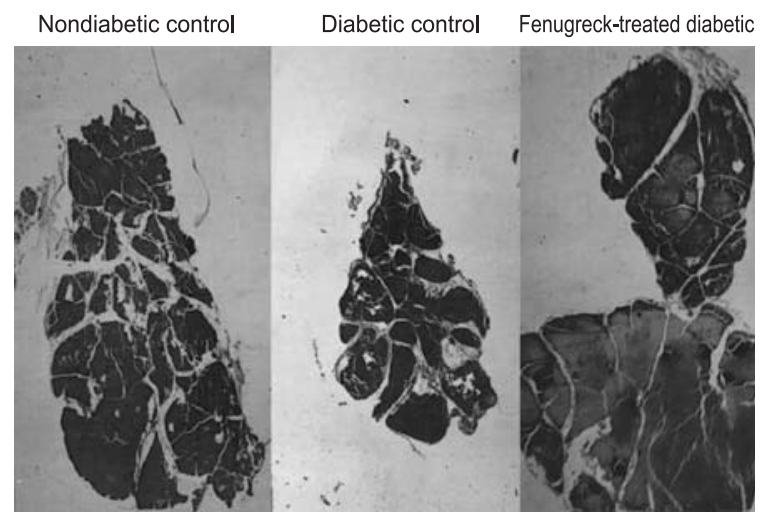

Final body weight $85 \mathrm{~g}$ Final body weight $110 \mathrm{~g}$ Final body weight $108 \mathrm{~g}$ thymic weight $225 \mathrm{mg}$ thymic weight $270 \mathrm{mg}$ thymic weight $335 \mathrm{mg}$ Thymic volume $0.20 \mathrm{ml}$ Thymic volume $0.25 \mathrm{ml}$ Thymic volume $0.30 \mathrm{ml}$

Fig.-1: Representative photographs of the thymic sections from three groups of rat showing prominently stained parenchyma and intervening spaces containing connective tissue. Respective body weight, thymic weight and thymic volume are also stated. The thymic section from the diabetic control group show a general trend of smaller size (involution) with more connective tissue than those from nondiabetic control group. On the other hand, thymic section of the fenugreek-treated diabetic group show a general trend of larger size with less connective tissue than those from diabetic control group, close to size and the amount of connective tissue in the thymic section from nondiabetic control group. 


\section{Discussion:}

In this study, Streptozotocin-induced diabetes in rats was associated with a marked increase in amount of connective tissue in histological section of the thymus. Drugs and pathological conditions impairing insulin production and secretion by pancreatic â-cells caused diabetes mellitus, which causes atrophy of the rat thymus gland. This atrophy is due to loss of thymocytes from the gland. ${ }^{6-9}$

In the thymus without involution the amount of connective tissue are scanty. During the early involution stage the amount of connective tissue will increase with a tendency to accumulate at the periphery of the lobule. In the later stage there is an increase in the amount of connective tissue even when involution is complete the amount of connective tissue is more.

Chatamara et al., has found that, histologically the cortex of the thymus was clearly reduced in width by the third day after the induction of diabetes with STZ. There is slight increase in the amount of connective tissue in the fibrous septa and capsule of the thymus by 3rd day after STZ-induced diabetes in rats. After 20 days, a marked increase in the amount of connective tissue in both the thickened fibrous septa and capsule was noted. By seventh day, this change was pronounced with thickening of connective tissue matrix. ${ }^{6}$

Tabata et al., has also found that in their histological findings, the cortical region of the thymus of diabetic rat was obviously reduced in size. Cortical lymphocytes present in the vicinity of the corticomedullary junction appeared to be reduced selectively. Similar changes was not seen in insulintreated diabetic rats. ${ }^{9}$

Islam $\mathrm{MN}^{10}$. has also observed that fenugreek can act against streptozotocin-induced diabetes to prevent reduction of size of pancreatic islets in addition to reduction of blood glucose level. He even suggested possible regeneration of â -cell with fenugreek treatment of STZ-induced diabetes in rats.

As defatted fenugreek powder has been used as the antidiabetic agent in this experiment, it has found that the diabetic condition of the rats has improved with possible regeneration of the â-cell of the pancreas to resume the insulin production as in normal condition ${ }^{10}$ with possible prevention of increment in amount of connective tissue in the thymic section in streptozotocin-induced diabetic rats.

\section{Conclusion:}

Defatted fenugreek showed a tendency of acting against the increased in amount of connective tissue in thymic section in diabetes mellitus. However, further investigations are recommended for establishing fenugreek as a safe, useful effective agent to minimize the increment in amount of connective tissue in thymic section improving the diabetic condition by acting as antidiabetogenic agent.

\section{References:}

1. Sharma RD. Effect of fenugreek seeds and leaves on blood glucose and serum insulin responses in human subjects. Nutr Res 1986; 6: 1353-64.

2. Mishkinisky J, Joseph B, Sulman FG, Goldschmied AL, Hypoglycaemic effect of trigonelline. Lancet 1967; 2: 1311-2.

3. Madar Z, Abel R, Samish S, Arad J. Glucose lowering effect of fenugreek in noninsulin dependent diabetes. Eur J Clin Nutr 1988; 42: 51-4.

4. Sharma RD, Raghuram TC. Hypoglycaemic effect of fenugreek seeds in non-insulin dependent diabetic subjects. Nutr Res 1990; 10: 731-9.

5. Sharma RD, Raghuram TC, Rao NS. Effect of fenugreek seeds on blood glucose and serum lipids in type-I diabetes. Eur J Clin Nutr 1990; 44: 301-6.

6. Chatamara K, Daniel PM, Kendal MD, Lam DKC. Comparison of histological changes in the thymus of fasted, streptozotocin diabetic and genetically diabetic rats with evidence that the enlarged adrenals in diabetes are not the cause of the atrophy in diabetic animals, $\mathrm{J}$ Physiol 1985; 353: 130.

7. Kinoshita Y, Tabata T, Kimura S, Toyakawa T, Okuno Y, Fujii S. Further study on the 
maturational impairment of the thymic lymphocytes in streptozotocin-induced diabetic rats from the view of peripheral lymphoid organs. Cell Mol Biol 1987; 33: 387-95.

8. Warley A, and Morris IW. Concentration of eliments in dying thymocytes from the thymus gland of diabetic rats, In: scanning microscopy 1988; 2: 2227-32.
9. Tabata T, Okuno Y, Fujii S, Kimura S, Kinoshita Y. Maturational impairment of thymic lymphocytes in streptozotocin-induced diabetes in Rats. Cell Immunol 1984; 89: 250-8.

10. Islam MN. Histological and biochemical effects of spirunina and Trigonellafoenumgraecum (fenugreek) on streptozotocin-induced diabetic rats [thesis], Dhaka: University of Dhaka. 1997. 